\title{
A PESQUISA SOBRE COOPETIÇÃO: EM DIREÇÃO A UMA MELHOR \\ COMPREENSÃO DO CONSTRUTO E SUA APLICAÇÃO NO TURISMO
}

RESEARCH ON COOPETITION: TOWARDS A BETTER UNDERSTANDING OF THIS CONSTRUCT AND ITS APPLICATION TO THE TOURISM SECTOR

LA INVESTIGACIÓN SOBRE COOPETICIÓN: RUMBO A UNA MEJOR COMPRENSIÓN DEL CONSTRUCTO Y SU APLICACIÓN EN TURISMO

\section{Adriana Fumi Chim-Miki}

Universidad de Las Palmas de Gran Canaria, Espanha

Pesquisadora da Universidad de Las Palmas de Gran Canaria, Espanha Doutora em Turismo, Economia e Gestão pela Universidad de Las Palmas de Gran

Canaria, Espanha Las Palmas de Gran Canaria, Las Palmas, Espanha adriana.chimmiki@gmail.com

Rosa Maria Batista-Canino

Universidad de Las Palmas de Gran Canaria, Espanha Professora no Programa de Doutorado de Turismo, Economia y Gestión da Universidad de Las Palmas de Gran Canaria, Espanha Doutora em Economia e Gestão e Licenciada pela Universidad de Las Palmas de Gran

Canaria, Espanha Las Palmas de Gran Canaria, Las Palmas, Espanha rosa.batistacanino@ulpgc.es

Data de Submissão: 20/03/2016

Data de Aprovação: 13/07/2016 
RESUMO: Este artigo apresenta uma revisão teórica do constructo coopetição, particularmente focando os estudos que aplicam este conceito no turismo. O objetivo é fornecer uma compreensão geral deste comportamento, que é apontado como gerador de uma nova classe de vantagens: as vantagens coopetitivas. A pesquisa é de corte teórico. É realizada uma análise sistemática da literatura por meio de uma bibliometria dos últimos 20 anos de publicações em duas bases de dados: Scopus e Web of Science. Desta forma, verificam-se as implicações da coopetição para o turismo, as delimitações do atual uso do constructo e se indicam as tendências futuras da pesquisa neste tópico. O resultado mostrou que a coopetição é vista como um constructo que representa o comportamento intrínseco do setor turístico, cujas empresas se complementam para formar um mercado, mas simultaneamente competem pela divisão dele. A existência de uma meta comum de desenvolver o destino é o maior indutor da coopetição, ocasionando a inseparabilidade entre a cooperação e a concorrência. Assim, a coopetição poderá ser uma perspectiva complementar para as análises de competitividade, porém necessita de mais pesquisas, especialmente que desenvolvam modelos explicativos para destinos turísticos.

PALAVRAS CHAVE: Coopetição Turística; Rede Interorganizacional; Vantagens coopetitivas.

ABSTRACT: This paper presents a theoretical review on the construct of coopetition (a neologism for cooperative competition), focusing particularly on studies that apply this concept to tourism. The goal is to provide a general overview of this behavior, which is indicated as a generator of a new class of advantage: coopetitive advantage. For this theoretical study, a systematic literature review was carried out on coopetition, through a bibliometric analysis of the last twenty years of publications in two databases: Scopus and Web of Science. The implications of coopetition for tourism, and the delimitations of the current use of the construct were verified. Also, future research tends on the topic are indicated. The result show that coopetition is seen as an intrinsic behavior of the tourism sector, where firms complement each other to create a market, while at the same time, competing for a share of it. The existence of the common goal of developing the tourism destination is the greatest driving force for coopetition, leading to inseparability between cooperation and competition. Thus, coopetition can be seen as a complementary perspective to competitiveness analysis; however more research on this topic is needed, especially to develop explanatory models for tourism destinations.

KEYWORDS: Tourism Coopetition; International Network; Coopetitive Advantages.

RESUMEN: Este artículo presenta una revisión teórica del constructo coopetición, particularmente enfocando los estudios que aplican este concepto en el turismo. El objetivo es proporcionar una comprensión general de este comportamiento, que es señalado como generador de una nueva clase de ventajas: las ventajas coopetitivas. La investigación es de corte teórico. Se realiza un análisis sistemático de la literatura por medio de una bibliometría de las publicaciones de los últimos 20 años en dos bases de datos: Scopus y Web of Science. De esta forma se verifican las implicaciones de la coopetición para el turismo, las delimitaciones del actual uso del constructo y se indican las tendencias futuras de la investigación de este tópico. El resultado mostró que la coopetición es vista como un constructo que representa el comportamiento intrínseco del sector turístico, cuyas empresas se complementan para formar un mercado, pero al mismo tiempo compiten por la división del mismo. La existencia de una meta común de desarrollar el destino es el mayor inductor de la coopetición, resultando en la inseparabilidad de la cooperación y la competencia. Así, la coopetición podrá ser una perspectiva complementaria para los análisis de competitividad, aunque necesita más investigaciones, especialmente que desarrollen modelos explicativos para destinos turísticos.

PALABRAS CLAVE: Coopetición Turística; Red Interorganizacional; Ventajas coopetitivas. 
$\sqrt{1} \begin{aligned} & \text { uitos estudos, tanto em âmbito da gestão organizacional } \\ & \text { como turística, focalizam a concorrência ou a cooperação } \\ & \text { como se fossem perspectivas antagônicas para a obtenção de }\end{aligned}$ vantagens competitivas (Della Corte \& Aria, 2016). No entanto, existem algumas linhas teórico-empíricas indicando que são perspectivas complementares que formam um construto denominado coopetição. O primeiro item é a tendência cada vez maior das empresas operarem em redes, buscando complementar suas habilidades e recursos. Neste sentido, a coopetição tem sido apontada como uma nova forma de fazer negócios (Brandenburger \& Nalebuff, 1996). Outro item é a plena consciência de que as empresas cooperam para obter vantagens ou benefícios (Luo, 2005), portanto cooperam para a criação de vantagens coletivas e concorrem pela apropriação destas vantagens em nível individual (Dagnino \& Padula, 2002).

A coopetição é um neologismo que define um comportamento híbrido de cooperação e concorrência dentro de uma organização, entre as organizações ou em escala de redes (LORGNIER; SU, 2014). No setor turístico, a coopetição é considerada praticamente uma necessidade de cooperar com os concorrentes para comercializar com mais eficácia o produto turístico e melhorar a competitividade do destino em nível regional ou global (Edgell \& Haenisch, 1995). Também é considerado um comportamento intrínseco ao destino turístico, pois mesmo que não seja intencional ou reconhecidamente utilizada como estratégia de gestão, a coopetição é o fundamento que move as redes organizacionais dos destinos turísticos (Della Corte \& Sciarelli, 2012).

Particularmente, o setor turístico possui características que são muito favoráveis à formação de redes de coopetição, como a alta atomização da oferta (grande número de micro e pequenas empresas), o elevado grau de complementariedade e interdependência entre as empresas (Della Corte \& Sciarelli, 2012), a presença de associações empresariais ou de organismos de governança e a existência de uma meta comum entre os stakeholders, que são o desenvolvimento do destino (Wang \& Krakover, 2008). Além disso, uma das 
ISSN: 1983-7151

condições de sucesso da rede de cooperação empresarial é a sua capacidade de gerar vantagens competitivas individuais a seus participantes. Nesta balança entre cooperação e competitividade se instala um sistema de coopetição.

O construto coopetição vem sendo estudado há vários anos e em vários setores. Porém, no âmbito da gestão e marketing dos destinos turísticos, este paradigma foi recentemente exposto (Kylänen \& Mariani, 2012). No entanto, a cooperação neste ambiente competitivo é considerada uma resposta natural e praticamente uma das poucas estratégias que pode ser utilizada para um desenvolvimento mais integrador do destino turístico (Fyall, Garrod \& Wang, 2012).

Ainda que seja um comportamento muito explicativo das redes interorganizacionais turísticas, existe uma carência de estudos com este enfoque. Este trabalho visa contribuir com a esta literatura, apresentando os principais aspectos que estão sendo estudados sobre coopetição e suas aplicações ao turismo. Desta forma, este estudo poderá contribuir para que outros pesquisadores utilizem este compêndio de informações para seguir na construção deste paradigma. A revisão teórica realizada oferece uma visão geral deste construto e destaca as principais pesquisas empíricas realizadas no turismo publicadas nas bases de dados Scopus e Web of Science entre o período de 1996-2015. A técnica utilizada para esta análise sistemática da literatura foi a bibliometria, que é um método usado para mapear como está se estruturando o conhecimento num determinado tópico ou âmbito de conhecimento, permitindo analisar o comportamento dos pesquisadores e estabelecer a tendência futura dos estudos (Vanti, 2002).

\section{FUNDAMENTOS TEÓRICOS DA COOPETIÇÃO}

A linha cronológica empresarial do uso da terminologia coopetição começou na década de 1910, cunhada pela estratégia de negócios da empresa Sealshipt Oyster (Cherington, 1913). Mas foi em 1980 que o empresário Raymond Noorda, no contexto da indústria tecnológica, deu notoriedade ao construto para explicar a estratégia empresarial da companhia Novell, considerando que era competir e cooperar ao mesmo tempo (RUSKO, 2011). 
Academicamente, o constructo começou a receber atenções desde a obra "Co-opetition: A revolutionary mindset that combines competition and cooperation in the marketplace", de autoria de Brandenburger e Nalebuff (1996). Nesta obra, os autores consideraram coopetição como uma nova forma de pensar os negócios, sendo relações multifacetadas entre empresas concorrentes, fornecedores, empresas complementarias e clientes. No entanto, um ano antes da publicação desta obra, que foi considerada como ponto de partida dos estudos de coopetição, Edgell e Haenisch (1995) haviam publicado o livro denominado de 'Coopetition: Global Tourism beyond the Millennium' para um público não acadêmico. Neste livro, os autores defendiam a coopetição como um comportamento necessário para que o turismo se desenvolvesse e atingisse as aclamadas predições econômicas do setor.

A ideia central é derivada da Teoria de Jogos (Von Neumann \& Morgenstern, 1994), que é considerada muito eficaz quando existem fatores interdependentes e nenhuma decisão pode ser tomada separadamente. Assim, a coopetição é uma aposta por múltiplos ganhadores, sendo um jogo de tensões construtivas entre agentes que competem e cooperam para obter benefícios mútuos, o qual é considerado um comportamento coerente dentro de um sistema econômico (Padula \& Dagnino, 2007). Para o destino turístico, a coopetição é considerada como a formação de redes que auxiliam na geração de um equilíbrio entre a concorrência e a colaboração, aumentando o rendimento do destino e de seus stakeholders (Van Der Zee \& Vanneste, 2015).

A bibliografia de diversas áreas aponta a coopetição como uma estratégia de negócios que está além dos paradigmas atuais (Kylänen \& Mariani, 2012), sendo uma nova forma de ver a cooperação interorganizacional sob a plena consciência de que sempre existe um grau de competição por benefícios diretos ou indiretos entre os participantes de uma redee, portanto, é um comportamento híbrido (Luo, 2005, 2007). Ao longo dos anos, seu conceito inicial foi evoluindo, partindo de uma simples definição de 'competir + cooperar simultaneamente', para uma ampla visão de rede de valor. Nesta evolução o conceito de coopetição passou a considerar questões como a existência de metas congruentes para abrir mercados (Bengtsson \& Kock, 2000) e o grau de interdependência entre os participantes da rede (Luo, 2004). As perspectivas passaram de um ponto 
ISSN: 1983-7151

em que a coopetição era tratada como um comportamento, para considerála como um sistema ou uma estratégia de gestão (Dagnino, 2012). Portanto, entrando na fase de considerá-la dentro das redes verticais, horizontais e mistas, assim como entre as redes (Bengtsson \& Kock, 2014). Atualmente, já se aponta a coopetição como sendo a formação de um novo paradigma (Kylänen \& Mariani; 2012; Chim-Miki \& Batista-Canino, 2015; Della Corte \& Aria, 2016).

Por outro lado, a cooperação interorganizacional em redes de empresas tem sido estudada por várias perspectivas, gerando uma literatura fragmentada em que diferentes tipos de abordagens, motivos e nomes foram dados ás relações de cooperação em redes empresariais, como: Integração vertical (Krippaehne et al., 1992); Co-work (Botsman \& Rogers, 2011; Deguzman \& Tang, 2011), alianças (Contractor \& Lorange, 1988; Norman, 2002), partnering (Crowley \& Karim, 1995; Wang \& Krakover, 2008), associativismo (Mohr \& Spekman 1994), associativismo estratégico (Ellison \& Miller, 1995), redes de organizações colaborativas (Collaborative Network Organizations - CNOs) (Camarinha-Matos \& Afsarmanesh, 2006).

Em concreto, Luo (2005) considera que os participantes se envolvem em redes de cooperação interorganizacional para melhorar suas capacidades individuais, portanto podem-se considerar todas estas perspectivas de cooperação sob os pressupostos teóricos da coopetição. Neste sentido, os fatores de êxito para estas redes são estudados na literatura, especialmente considerando a compatibilidade entre os participantes e os objetivos compartilhados, a confiança mútua, o compromisso entre os atores, o equilíbrio de poder e controle, as semelhanças culturais, etc. (Ring \& Van De Ven,1994). Direcionando ao turismo, verifica-se que a forma produtiva do destino turístico varia conforme sua organização, estando muitas vezes representado como rede, cluster, distrito ou aglomerado produtivo local, etc. No entanto, em praticamente todos os casos existe uma rede interorganizacional que coopera e concorre na sua formação, sendo então uma rede coopetitiva.

Sintetizando os aportes teóricos de vários autores e oferecendo um conceito integral para esteconstructo, considera-sequea coopetiçãoéum comportamento híbrido de cooperação-competitiva que ocorre entre redes, organizações ou dentro de organizações, incluindo as relações entre concorrentes, fornecedores, 
empresas complementarias, agências governamentais, população local e clientes, sendo resultado de ações conjuntas para atingir objetivos comuns, apesar de interesses individuais; enquanto que para um destino a coopetição turística é um comportamento híbrido de cooperar e competir simultaneamente que ocorre entre dois ou mais atores do destino turístico com o fim de promover seu desenvolvimento como produto integral.

\section{RESULTADOS}

As próximas duas seções sintetizam os resultados do estudo bibliométrico realizado, seguido de um detalhamento da revisão teórica dos estudos que aplicaram este construto no turismo.

\section{COOPETIÇÃO: STATUS DA PESQUISA ATUAL}

Verificando as duas maiores bases de dados de literatura anônima revisada e disponível em websites de qualidade - SciVerse Scopus e Web of Science (MEHO; YANG, 2007), verificara-se algumas características da pesquisa em coopetição. Para localizar os estudos publicados sobre esta temática, foram realizadas duas buscas nas bases de dados anteriormente citadas, com critérios predefinidos. Primeiro se buscaram artigos em que as palavras "Coopetition ou Co-opetition" estivessem no título, no resumo ou nas palavras-chaves do artigo. Num segundo momento, afunilou-se a busca para se concentrar no setor turístico. Assim, utilizaram-se as palavras "Tourism Coopetition ou Tourism Co-opetition". O recorte temporal estabelecido foi de trabalhos publicados entre 1996 a 2015, ambos inclusive. Alguns artigos apareciam nas duas bases de dados, assim foram desconsiderados os casos de duplicidade. O resultado final depurado foi de 284 publicações sobre coopetição em diversos setores (Gráfico 1). Destes 284 artigos, 199 são estudos empíricos, sendo a maioria no setor industrial (40,2\%). Consideraram-se na categoria 'empresas em geral' os trabalhos da área comercial ou que incluíam redes com mais de um setor. O turismo, apesar de estar dentro do setor de serviços, foi computado separadamente para fins de melhor adequação aos objetivos deste trabalho. 
Assim, este setor apresentou 7,5\% dos trabalhos empíricos, ou seja, entre as 199 publicações empíricas, 15 foram no setor turístico. Os demais setores podem ser observados no Gráfico1.

Gráfico 1: Setores econômicos de aplicação empírica da pesquisa sobre coopetição publicada entre 1996 a 2015 nas bases de dados Scopus e Web of Science

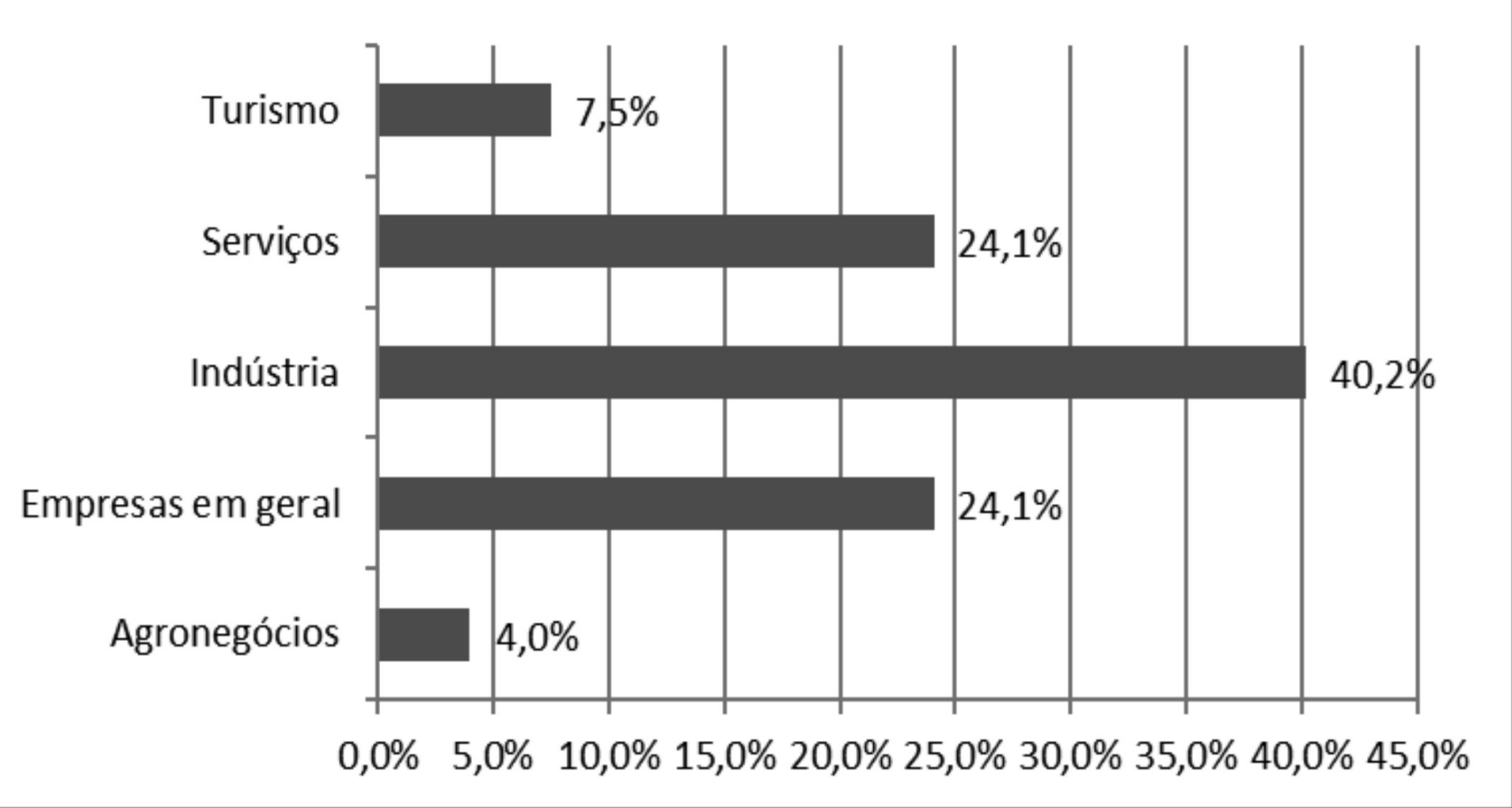

Fonte: Elaboração própria.

Os artigos, na grande maioria, possuem mais de um autor, gerando um total de 506 pesquisadores, cuja maior concentração está afiliada a universidades do continente europeu (43,7\%), seguido do continente americano (28,5\%). A Ásia participa com 24,3\%, Oceania com 3,3\% e África com 0,2\% dos pesquisadores desta amostra. Os dez países que encabeçam a lista representam a maioria dos pesquisadores (72\%), a saber: Estados Unidos (118 pesquisadores), China (64), França (49), Reino Unido (24), Finlândia (23), Taiwan (22), Itália (18), Brasil (16), Espanha (15) e Suécia (15). Quanto aos estudos específicos de coopetição em turismo, metade está publicada em revistas de turismo e outra metade em revistas de gestão, sendo que a maioria dos pesquisadores é afiliada a universidades europeias ou estadunidenses.

A evolução de número de trabalhos publicados tem sido constante, indicando que há um crescente interesse sobre esta temática e que se acentuou nos dois últimos anos. No turismo, existem vários anos sem publicações, mas nos últimos cinco anos a temática entrou na agenda de estudo dos pesquisadores (Gráfico 2). 
Gráfico 2: Evolução do número de artigos publicados sobre coopetição entre 19962015 nas bases de dados Scopus e Web of Science

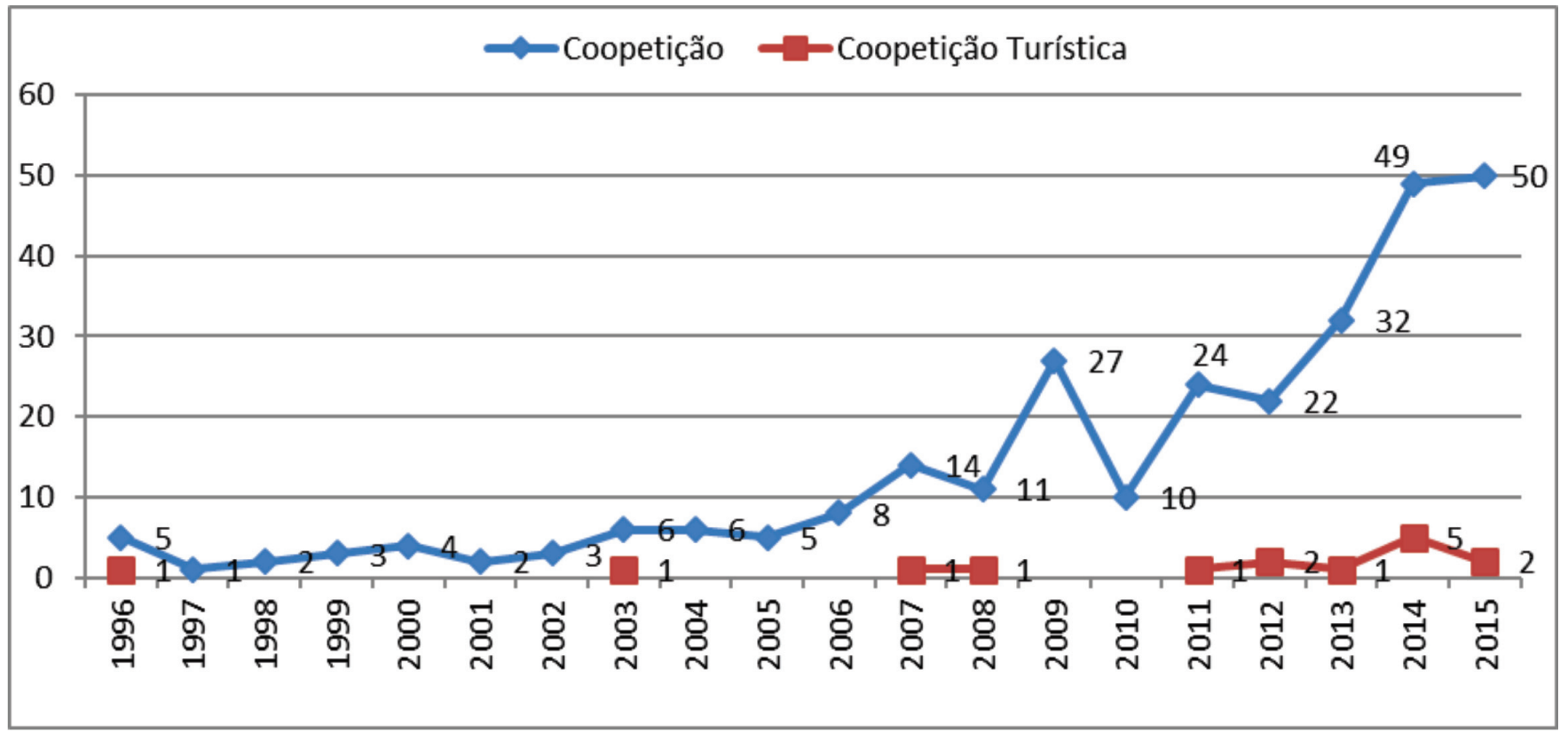

Fonte: Elaboração própria.

Os estudos apresentam diversos outros construtos que são relacionados à coopetição como resultado ou como fatores indutores deste comportamento e também abordam este comportamento em nível intra e interorganizacional. Della Corte e Aria (2016) consideram que os estudos de coopetição podem ser divididos nos que abordam a intensidade, a tipologia e os impactos. Anteriormente, Bengtsson e Kock (2014) também categorizaram os estudos, considerando que alguns estudam a probabilidade, a interação, o processo ou os resultados da coopetição. O Quadro 1 apresenta alguns exemplos de modelos de coopetição encontrados na literatura deste período, dividindo-os segundo a classificação de estudos definida por Bengtsson e Kock (2014).

Quadro 1: Modelos de coopetição - principal foco e autores

\begin{tabular}{|c|c|}
\hline Tipo de Modelo & Autores \\
\hline $\begin{array}{c}\text { Modelos de rede } \\
\text { de coopetição } \\
\text { para identificar } \\
\text { e explicar } \\
\text { mecanismos } \\
\text { que induzem o } \\
\text { comportamento } \\
\text { dos participantes } \\
\text { da rede }\end{array}$ & $\begin{array}{c}\text { Principal foco: Probabilidade e Interação } \\
\text { Modelo PARTS de Brandenburger e Nalebuff (1996); } \\
\text { Modelo de coopetição multi-unidade de Tsai (2002); } \\
\text { (2008); } \\
\text { Modelo de fatores de relações de coopetição em turismo de Wang e Krakover } \\
\text { Modelo de fatores de êxito em estratégias de coopetição de Chin et al. (2008); } \\
\text { Modelo de fatores críticos da coopetição em redes horizontais de Hermes et al. } \\
\text { (2013); } \\
\text { Modelo paradoxal da tensão coopetitiva de Raza-Ullah et al. (2014); } \\
\text { Modelo de gestão de tensões coopetitivas de Fernandez et al. (2014). }\end{array}$ \\
\hline
\end{tabular}




\begin{tabular}{|c|c|}
\hline $\begin{array}{l}\text { Modelos de } \\
\text { tipologias de } \\
\text { coopetição para } \\
\text { apresentar níveis } \\
\text { de intensidade } \\
\text { coopetitiva }\end{array}$ & $\begin{array}{c}\text { Principal foco: Processo } \\
\text { Modelo de relações coopetitivas de Bengtsson e Kock (2000); } \\
\text { Modelo integrado de coopetição inter unidades de multinacionais de Luo (2005); } \\
\text { Modelo de escala de intensidade de coopetição de Luo (2007); } \\
\text { Modelo de linha de continuidade de coopetição de Eriksson (2008); } \\
\text { Modelo de relações de coopetição horizontal de Wilhelm (2011); } \\
\text { Modelo de tipologias de coopetição de Rusko (2011); } \\
\text { Modelo de coopetição vertical de Lacoste (2012); } \\
\text { Modelo de estratégias de recursos para coopetição de Huang e Chu (2015). }\end{array}$ \\
\hline $\begin{array}{l}\text { Modelos de } \\
\text { resultado do uso } \\
\text { de coopetição } \\
\text { para definir } \\
\text { a relação da } \\
\text { coopetição sobre } \\
\text { a melhoria de } \\
\text { performance da } \\
\text { empresa ou da } \\
\text { rede }\end{array}$ & $\begin{array}{l}\text { Principal foco: Resultados } \\
\text { Modelo de coopetição Inter-funcional de Luo et al. (2006); } \\
\text { Modelo conceitual de coopetição para inovação tecnológica em micro e pequenas } \\
\text { empresas de Gnyawali e Park (2009); } \\
\text { Modelo de coopetição em inovação de Ritala e Humerlinna-Laukkanen (2009); } \\
\text { Modelo de efetividade laboral em coopetição para equipes virtuais de Lin et al. (2010); } \\
\text { Modelo de coopetição para rendimento de equipes virtuais de Baruch e Lin (2012); } \\
\text { Modelo de coopetição para intercâmbio de conhecimento de Ghobadi e D'Ambra (2012); } \\
\text { Modelo de tipo de governança em alianças tecnológicas baseado em coopetição de } \\
\text { Hung e Chang (2012); } \\
\text { Modelo de rentabilidade turística baseado em coopetição de Della Corte e Sciarelli (2012); } \\
\text { Modelo de inovação incremental e radical promovidas por coopetição de Ritala e } \\
\text { Humerlinna-Laukkanen (2013); } \\
\text { Modelo de impacto de estratégias de coopetição no varejo de Kim et al. (2013); } \\
\text { Modelo de inovação baseado em coopetição para empresas de conhecimento } \\
\text { intensivo de Bouncken e Kraus (2013); } \\
\text { Modelo do impacto da coopetição sobre a inovação de Park et al. (2014); } \\
\text { Modelo de coopetição para criar e sustentar oportunidades em pequenas empresas } \\
\text { de Bengtsson e Johansson (2014); } \\
\text { Modelo de resiliência organizacional baseado em coopetição de Borekci et al. (2015); } \\
\text { Modelo de coopetição para uma distribuição sustentável de Limoubpratum et al. (2015); } \\
\text { Modelo de coopetición para agilidade e rendimento de equipes de Liu et al. (2015). }\end{array}$ \\
\hline
\end{tabular}

Fonte: Elaboração própria.

\section{COOPETIÇÃO TURÍSTICA: ABORDAGENS DOS ESTUDOS EMPÍRICOS}

Nesta amostra de artigos estudados, os 15 trabalhos empíricos que se realizaram no setor turístico (Quadro 2) têm abordagens bem diferenciadas, ainda que algumas características em comum, especialmente relacionadas a perspectivas de: interdependência, complementariedade, co-localização e redes colaborativas do turismo.

O Quadro 2 sintetiza os 15 estudos que foram identificados nas bases de dados anteriormente citadas que continham a palavra coopetição no título, palavras-chaves ou resumo do artigo e eram aplicações empíricas no turismo.

Quadro 2: Resumo dos artigos publicados sobre coopetição turística entre 19962015 nas bases de dados nas bases de dados Scopus e Web of Science 


\begin{tabular}{|c|c|}
\hline Título artigo/Autores/Ano & Proposta/objetivo/resultado \\
\hline $\begin{array}{c}\text { Coopetition: Global tourism beyond } \\
\text { the Millennium } \\
\text { Taylor (1996) }\end{array}$ & $\begin{array}{c}\text { Book Review do livro "Coopetition: Global Tourism beyond the } \\
\text { Millennium". }\end{array}$ \\
\hline $\begin{array}{l}\text { Destination networking: } \\
\text { Co-opetition in peripheral } \\
\text { surroundings } \\
\text { Von Friedrichs Grängsjö (2003) }\end{array}$ & $\begin{array}{c}\text { Discutir a teoria coopetitiva de negócios baseada no estudo de redes de } \\
\text { comercialização de um destino dominado por microempresas e empresários } \\
\text { independentes. O resultado indicou dois conjuntos diferentes de valores no } \\
\text { destino e que estes conjuntos determinam a forma como as empresas se } \\
\text { involucram nas relações da rede coopetitiva. }\end{array}$ \\
\hline $\begin{array}{l}\text { The determinants of cluster } \\
\text { activities in the Australian wine } \\
\text { and tourism industries } \\
\text { Taylor, Mcrae Williams \& Lowe (2007) }\end{array}$ & $\begin{array}{l}\text { Verifica o comportamento das empresas de produção de vinho e as } \\
\text { organizações de turismo que operam nesta área, formando um cluster } \\
\text { de enoturismo. Examina o conceito de micro cluster e a confiança mútua. } \\
\text { Os resultados indicaram que o tipo de atividade/setor é mais importante } \\
\text { para determinar a coopetição do que a formação de aglomerados } \\
\text { produtivos, pois as empresas de produção de vinho participam mais de } \\
\text { atividades de cooperação do que as empresas de turismo. }\end{array}$ \\
\hline $\begin{array}{l}\text { Destination marketing: } \\
\text { Competition, cooperation or } \\
\quad \text { coopetition? } \\
\text { Wang \& Krakover (2008) }\end{array}$ & $\begin{array}{c}\text { Apresenta uma análise das relações entre empresas de um destino } \\
\text { turístico em atividades de colaboração para o marketing do destino. } \\
\text { O resultado indicou que diferentes relações de cooperação, } \\
\text { concorrência e coopetição coexistem entre os agentes do turismo, } \\
\text { assim como diferentes graus de formalização, integração e } \\
\text { complexidade na estrutura das redes. }\end{array}$ \\
\hline $\begin{array}{l}\text { Unintentional coopetition in the } \\
\text { service industries: The case of } \\
\text { Pyha-Luosto tourism destination } \\
\text { in the Finnish Lapland } \\
\text { Kvlänen \& Rusko (2011) }\end{array}$ & $\begin{array}{l}\text { Analisa a coopetição intencional e não intencional em regiões turísticas } \\
\text { que compartilham fronteiras geográficas. Os resultados indicam vantagens } \\
\text { derivadas do uso de coopetição para o desenvolvimento turístico de regiões } \\
\text { fronteiriças e com atrações ou recursos compartilhados. }\end{array}$ \\
\hline $\begin{array}{l}\text { Can coopetition be the source } \\
\text { of competitive advantage for } \\
\text { strategic networks? } \\
\text { Della Corte \& Sciarelli (2012) }\end{array}$ & $\begin{array}{l}\text { Verifica se as relações de coopetição são fonte de vantagens competitivas } \\
\text { ou de desvantagem para as empresas envolvidas na rede coopetitiva. Os } \\
\text { resultados, obtidos a partir de uma investigação sobre empresas que operam } \\
\text { na indústria de turismo italiana, indicam que ambos os casos existem e } \\
\text { dependem de uma adequada gestão para que se maximizem as vantagens, } \\
\text { bem como de um adequado preparo da empresa para que possa apropriar- } \\
\text { se do valor criado pelo esforço coletivo da rede. }\end{array}$ \\
\hline $\begin{array}{l}\text { Unpacking the temporal dimension } \\
\text { of coopetition in tourism } \\
\text { destinations: Evidence from Finnish } \\
\text { and Italian theme parks } \\
\text { Kylanen \& Mariani (2012) }\end{array}$ & $\begin{array}{l}\text { Analisa a dinâmica temporal das relações de coopetição interinstitucional } \\
\text { nos parques temáticos finlandeses e italianos. Os resultados indicam que as } \\
\text { empresas turísticas estabelecem primeiramente relações de coopetição em } \\
\text { curto prazo, o que proporcionam a compreensão das vantagens derivadas da } \\
\text { coopetição, como melhoria de imagem e atratividade do destino, gerando } \\
\text { uma continuidade nas relações e migrando a relações de longo prazo. }\end{array}$ \\
\hline $\begin{array}{l}\text { Trust and reciprocity in } \\
\text { building interpersonal and } \\
\text { interorganizational commitment } \\
\text { in small business cooperatives } \\
\text { Pesämaa, Pieper, Vinhas da Silva, } \\
\text { Black \& Hair (2013) }\end{array}$ & $\begin{array}{l}\text { Através de um modelo de equações estruturais analisam o compromisso } \\
\text { interorganizacional e interpessoal no contexto de cooperativas de pequenas } \\
\text { empresas turísticas. Os resultados indicam o papel da confiança mútua e } \\
\text { da reciprocidade como percursores do compromisso para a cooperação } \\
\text { interempresarial. O trabalho não aborda a coopetição diretamente, mas cita } \\
\text { esta terminologia no resumo do artigo e trata-a de forma tangencial. }\end{array}$ \\
\hline $\begin{array}{l}\text { Considering coopetition strategies } \\
\text { in sport tourism networks: a look at } \\
\text { the nonprofit nautical sports clubs } \\
\text { on the northern coast of France } \\
\text { Lorgnier \& Su (2014) }\end{array}$ & $\begin{array}{l}\text { Os autores realizam uma análise DAFO (Debilidades, Ameaças, } \\
\text { Fortalezas e Oportunidades), com objetivo de verificar a co-criação de } \\
\text { valor em redes B2B (Business-to-Business) que utilizam estratégias de } \\
\text { coopetição no setor de turismo de esportes. }\end{array}$ \\
\hline $\begin{array}{l}\text { On line Coopetition between hotels } \\
\text { and online travel agencies: From } \\
\text { the perspective of cash after stay } \\
\text { Guo, Zheng, Ling \& Yang (2014) }\end{array}$ & $\begin{array}{c}\text { Estuda o aumento da quota de mercado através da formação de } \\
\text { redes de cooperação entre agências de viagens on-line. Os resultados } \\
\text { indicam que se forma coopetição e este comportamento é o que } \\
\text { equilibra a rede. }\end{array}$ \\
\hline
\end{tabular}




\begin{tabular}{|c|c|}
\hline $\begin{array}{l}\text { Orígenes, elementos } \\
\text { determinantes y resultados de un } \\
\text { exitoso proceso de colaboración } \\
\text { entre competidores y otros } \\
\text { agentes: El clúster de la Alta } \\
\text { Cocina Vasca } \\
\text { Aldamiz-Echevarría, Soledad } \\
\text {-Aguirre \& Gloria Aparicio (2014) }\end{array}$ & $\begin{array}{l}\text { Analisa os fatores que promovem a geração de um cluster turístico } \\
\text { e mantém seu êxito. Um dos fatores indicados nos resultados é o } \\
\text { comportamento de coopetição entre os stakeholders. }\end{array}$ \\
\hline $\begin{array}{l}\text { Local stakeholders' views about } \\
\text { destination management: who is } \\
\text { leading tourism development? } \\
\text { Tuohino \& Konu (2014) }\end{array}$ & $\begin{array}{l}\text { Analisa diferentes tipologias de cooperação nas redes turísticas, relacionando } \\
\text { a governança do destino com a coopetição. A partir de uma análise realizada } \\
\text { em três destinos turísticos, foi verificado que a liderança é dependente } \\
\text { do contexto e gera diferentes formas de comportamento numa escala de } \\
\text { concorrência, cooperação e coopetição. }\end{array}$ \\
\hline $\begin{array}{l}\text { Something old is new again: } \\
\text { Airline airport consortia and key } \\
\text { stakeholder benefits } \\
\text { Tinoco \& Sherman (2014) }\end{array}$ & $\begin{array}{c}\text { Analisa a formação de consórcios aéreos, considerando-os como } \\
\text { estratégia de coopetição. Os resultados indicam evidências positivas } \\
\text { para todos os stakeholders, mas não fica claro quanto destes } \\
\text { benefícios se transmitem ao passageiro. }\end{array}$ \\
\hline $\begin{array}{l}\text { Coopetition and Knowledge } \\
\text { Transfer Dynamics: New Zealand's } \\
\text { Regional Tourism Organizations } \\
\text { and the } 2011 \text { Rugby World Cup } \\
\text { Werner, Dickson \& Hyde (2015) }\end{array}$ & $\begin{array}{c}\text { Realiza uma análise da Copa do Mundo de Rúgbi (RWC) } 2011 \text { na Nova } \\
\text { Zelândia, considerando as relações de coopetição entre as organizações } \\
\text { regionais de turismo (RTO). Os resultados indicam que elas colaboram entre } \\
\text { si como parte do desenvolvimento do enfoque nacional para o evento, mas } \\
\text { competem pela atração do turista. Também indica que a coopetição afeta } \\
\text { negativamente a dinâmica de transferência do conhecimento entre as RTO } \\
\text { no contexto deste megaevento. }\end{array}$ \\
\hline $\begin{array}{l}\text { Tourism networks unravelled; } \\
\text { a review of the literature on } \\
\text { networks in tourism management } \\
\text { studies } \\
\text { Van Der Zee \& Vanneste (2015) }\end{array}$ & $\begin{array}{l}\text { Apresenta uma visão geral do status da pesquisa sobre redes } \\
\text { turísticas. O objetivo foi obter uma melhor compreensão do } \\
\text { porquê as promessas teóricas de benefícios potenciais derivados } \\
\text { de colaboração entre atores do destino turístico estão tão pouco } \\
\text { apoiadas em evidencias empíricas. Os resultados indicam que a } \\
\text { falta de uma metodologia integrada e de construtos apropriados } \\
\text { ao turismo são itens que geram uma dispersão do conhecimento } \\
\text { e uma amplitude de análise que dificulta a evolução do próprio } \\
\text { conhecimento sobre redes turísticas e seus efetivos resultados. }\end{array}$ \\
\hline
\end{tabular}

Fonte: Elaboração própria.

Do Quadro 2 extrai-se que os estudos de turismo, apesar de ainda serem poucos nesta perspectiva de coopetição, estão abrindo uma nova frente de análise sobre algumas práticas usuais nos destinos turísticos, como formação de redes, clusters, governança e consciência do associativismo e suas vantagens, além do que este construto é a real base das ações de co-marketing e de cocriação de valor, as quais são comuns nos destinos turísticos, pois se derivam do alto grau de interdependência e complementariedade existente na oferta turística de um destino. Este contexto pode gerar estratégias de gestão que incentivam a confiança mútua e a intencionalidade para coopetir, trazendo resultados positivos aos participantes e a todo o destino (Figura 2).

Figura 1: Síntese das principais perspectivas abordadas nos estudos de coopetição turística 


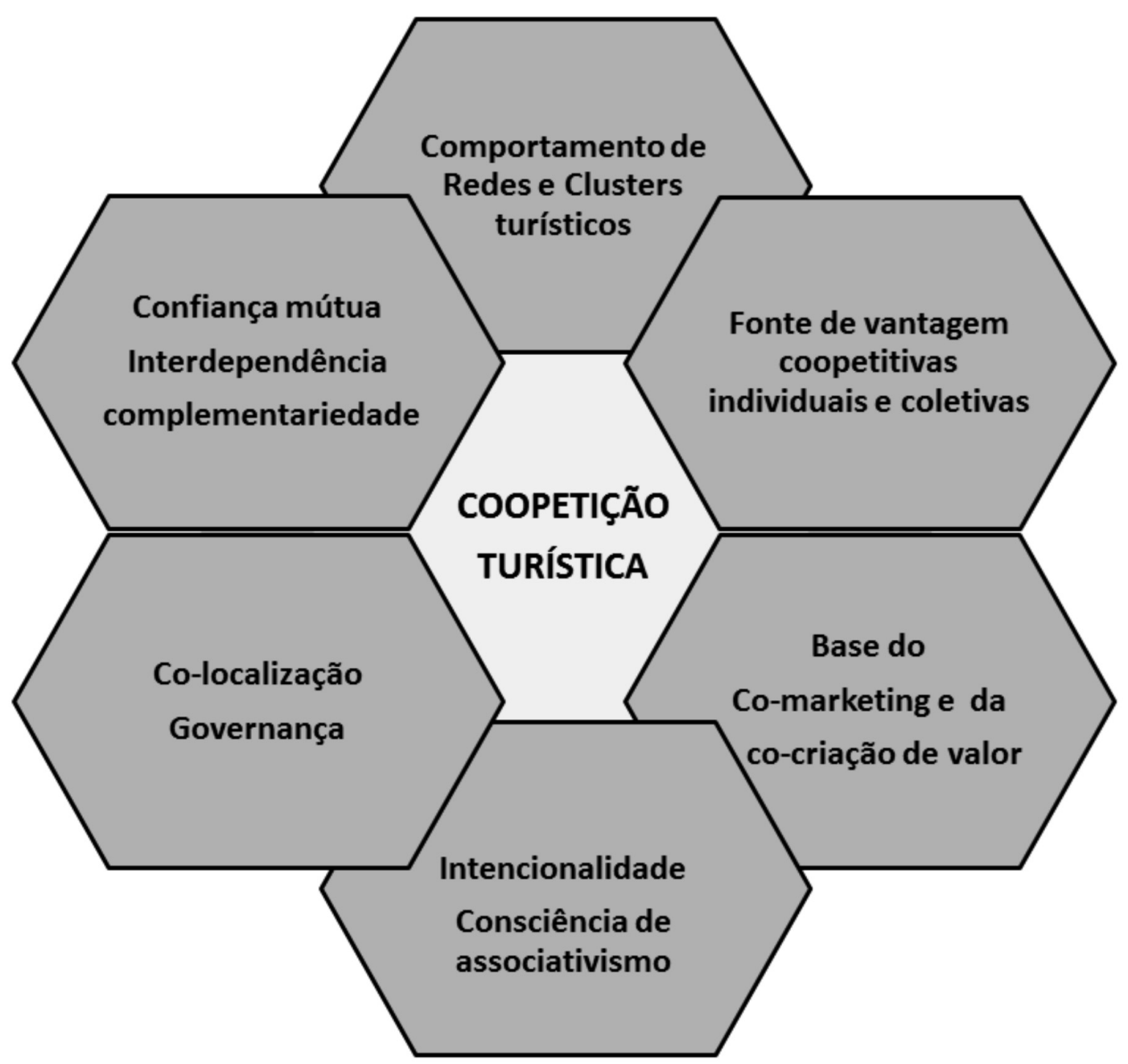

Fonte: Elaboração própria.

Em geral, nos estudos de turismo, a perspectiva de cooperação ou colaboração tem sido muito estudada (Fyall et al. 2012; Della Corte \& Aria, 2016), assim como a perspectiva de competitividade sobre uma base porteriana (Ritchie \& Chouch, 2003) ou sobre uma base da Teoria de Recursos e Capacidades (Barney, 1991). A análise bibliométrica realizada por Van der Zee e Vanneste (2015) sobre estudos de redes de colaboração em destinos turísticos indicou que o progresso dos estudos nesta área em turismo está obstaculizado pela falta de integração metodológica e de definições nos estudos de redes turísticas. Também indicou que existem vários subcampos de pesquisa, entre os quais se encontra a coopetição, a qual os autores apontam como sendo um comportamento mais realista das relações de colaboração dentro do destino turístico.

Esta revisão bibliográfica mostrou que, atualmente, na grande maioria dos destinos turísticos, a cooperação não se dissocia mais da concorrência, como nos trabalhos de Von Friedrichs Grängsjö (2003) e Wang e Krakover (2008). Isto corrobora a visão de que a gestão adequada do destino turístico deve 
ISSN: 1983-7151

ser através de um sistema de governança ou utilizando uma organização de gestão do destino (DMO-Destination Management Organization). Estas formas são nada menos que redes interorganizacionais de coopetição, já que incluem empresas concorrentes, complementarias, fornecedoras, organismos institucionais público e privado e, quando alcançam um nível de governança, incluem a população local (Tuohino \& Konu, 2014).

O destino turístico passa a ser uma unidade de análise e de gestão integrada, pois aos olhos do consumidor é um produto único (Timon, 2004), sendo assim exige uma estratégia que o considere como um empreendimento coletivo. Neste sentido, Fyall et al. (2012) classificam o comportamento das redes dentre do destino turístico segundo o alcance da colaboração e a intermediação de um organismo gestor e facilitador como uma DMO. Sua tipologia demonstra típicas relações de coopetição entre os stakeholders, pois considera que é colaboração orgânica quando ocorre dentro do destino ou entre destinos, podendo ou não ser intermediada por uma DMO. É o caso de uma rede composta por alguns estabelecimentos de hospedagem, por exemplo. Enquanto que a colaboração intra destinos e/ou inter destinos intermediada por uma DMO tem uma abrangência maior, pois inclui empresas em geral de um destino, ou ainda, entre destinos com atrativos compartilhados, podendo alcançar um nível de governança.

Também se verifica que a análise dos estudos turísticos utilizando a perspectiva de coopetição trabalha com duas linhas de observação do construto. Por uma parte a coopetição é tratada pelos pesquisadores como variável explicativa (independente) e por outra parte como variável explicada (dependente), relacionando-a com diversos outros construtos (Figura 1). Nos estudos analisados, o grau confiança tanto interpessoal como interorganizacional são destacados por vários autores como variáveis explicativas das relações de coopetição no turismo (ex. em Taylor, Mcrae-Williams \& Lowe, 2007; Pesämaa et al., 2013), assim como se destaca o grau de consciência sobre as vantagens colaborativas (ex. em Della Corte \& Sciarelli, 2012). A co-localização também é apontada nos estudos de turismo como um fator explicativo da coopetição, especialmente tratando-se de destinos vizinhos (ex. em Kylänen \& Mariani, 2012).

Salientam-se os estudos que analisam a variável intencionalidade em coopetir, pois se considera que em turismo muitas vezes a coopetição é emergente, não 
intencional e provocada por forças políticas e de mercado (ex. em Kylänen \& Rusko, 2011), no entanto seu uso constante pode evoluir a estratégias intencionais e botton-up. Neste sentido, considera-se como uma variável explicativa a temporalidade da relação entre os stakeholders (ex. em Kylänen \& Mariani, 2012). O contexto empresarial que indica o grau de cooperação e de concorrência interna no destino, o tamanho e a formalização da rede, e o nível de governança também foram estudados por Von Friedrichs Grängsjö (2003), Wang e Krakover (2008) e Tuohino e Konu (2014) como fatores determinantes da coopetição em destinos turísticos.

Por outro lado, existem estudos que tratam a coopetição como uma variável que explica o resultado de uma rede, sistema ou do destino turístico. Neste caso os estudos relacionam os resultados de melhoria de atratividade e imagem do destino (ex. em Kylänen \& Mariani, 2012), benefícios e melhoria da quota de mercado (ex. em Guo et al., 2014; Tinoco \& Sherman, 2014), sucesso na formação e manutenção de cluster turístico (ex. em Aldamiz-Echevarría et al., 2014), geração de conhecimento compartilhado (ex. em Werner, Dickson \& Hyde, 2015), co-criação de valor (ex. em Lorgnier \& Su, 2014) e vantagens competitivas tanto coletivas como individuais (ex. em Della Corte \& Sciarelli, 2012; Van der Zee \& Vanneste, 2015).

A escolha das variáveis indica que os estudos estão buscando definir o contexto que favorece a formação do comportamento coopetitivo no destino turístico, e por outro lado buscando estabelecer os resultados do uso desta estratégia de gestão.

Em geral, os estudos de coopetição se categorizam em nível individual, intraorganizacional, interorganizacional ou nível de inter-redes. Porém no turismo a grande maioria dos estudos analisados é interorganizacional ou interredes, havendo os casos de estudos de coopetição em nível de inter-destinos, como o estudo de Kylänen e Rusko (2012), que envolve destinos da região de Pyha-Luosto. No período analisado não foi encontrado nenhum estudo de coopetição em nível de intraorganizacinal em empresas turísticas, indicando que a coopetição está mais considerada para estudar as redes do destino em perspectiva macro. 
Figura 2: Variáveis explicativas e explicadas pela coopetição nos estudos turísticos

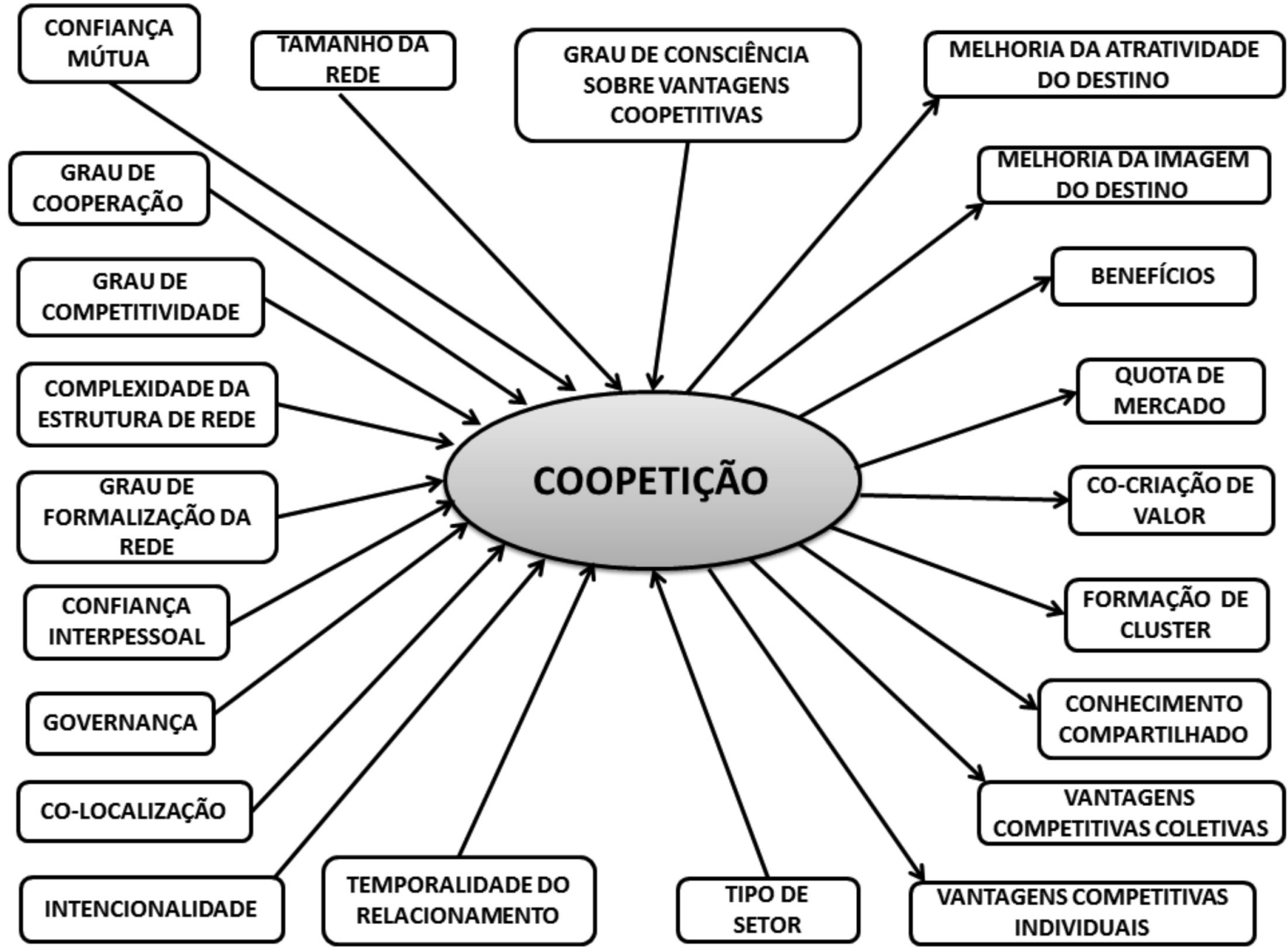

Fonte: Elaboração própria.

\section{CONSIDERAÇÕES FINAIS}

Este trabalho objetivou apresentar uma síntese de uma extensa revisão teórica que foi realizada sobre estudos de coopetição em várias áreas e especificamente focando no turismo. Pretendeu-se gerar uma melhor compreensão do uso deste construto no setor turístico, dando um panorama de como está sendo aplicado, considerando outro ângulo para o estudo das relações interorganizacionais e da competitividade de destinos turísticos. A inserção desta perspectiva teórica nos estudos de turismo poderá gerar bases para entender a formação das vantagens competitivas derivadas da perspectiva relacional.

A revisão da literatura sobre coopetição e especificamente coopetição turística permitiu constatar que o destino turístico é um sistema de coopetição, pois suas características geram um contexto que reproduz a formação de redes 
ou alianças interorganizacionais entre empresas horizontais, verticais e mistas, portanto a relação entre elas é um híbrido entre cooperação e concorrência (Della Corte \& Aria, 2016).

Este estudo indica uma perspectiva para se analisar o destino turístico, que vai mais além da clássica análise pela oferta ou pela demanda, ou, ainda, pela concorrência ou cooperação. A visão que se indica considera que mesmo entre empresas complementarias no destino turístico existe concorrência, pois o orçamento do turista é único, portanto ele tem que decidir entre as diversas ofertas do destino, assim as empresas de diferentes atividades competem pelo orçamento do turista (Chim-Miki \& Batista-Canino, 2015). Nesta visão, pode-se considerar que todas as relações no destino turístico são baseadas em concorrência, porém a formação de redes de cooperação objetivando uma meta comum de desenvolver o destino transforma estes relacionamentos em coopetição.

A interdependência e a complementariedade são fatores muito estudados nas relações de coopetição e presentes nos destinos turísticos, considerados tanto como fonte de criação do valor econômico como um lugar para a divisão deste valor. São as bases de um jogo de soma positiva, ou seja, que gera benefícios para todos. Porém deve ser observado que estes benefícios nem sempre são iguais (ou justos) por força das pressões competitivas e capacidades individuais de captação do valor coletivo criado (Dagnino \& Padula, 2002).

Também se observa que a coopetição é uma estratégia apontada como positiva para gerar oportunidades a micro e pequenas empresas (Bengtsson \& Kock, 2014), fato que pode contribuir ao desenvolvimento do destino turístico, pois existe uma grande atomização da oferta. Outra característica presente nos destinos turísticos é o grau de associativismo ou de formação de redes de colaboração, assim como a evolução destas redes a níveis de governança. Este contexto é basicamente coopetição turística.

Os estudos em coopetição apresentam categorias que analisam o contexto de formação deste comportamento, a dinâmica das redes e os resultados do uso desta estratégia tanto em nível intra como interorganizacional. Em especial para o turismo, este estudo demonstra que as pesquisas também seguem estas categorias identificadas por Bengtsson e Kock (2014). No entanto, até 
ISSN: 1983-7151

o presente momento os estudos focalizam mais em nível interorganizacional, ou seja, nas redes turísticas, especialmente se verificam estudos de coopetição entre destinos vizinhos ou que compartem atrativos (ex. Kylänen \& Mariani, 2012). Não se encontraram estudos de coopetição interorganizacional nas empresas turísticas.

Assim, esta revisão teórica indica que no turismo o construto coopetição segue uma tendência de ser uma perspectiva sistêmica, a qual é bastante adequada a estudos de destinos turísticos e seus componentes (Timon, 2004). Também a tendência de estudos indica que este construto poderá ser o início de um novo paradigma que ajudará a explicar o porquê que algumas regiões turísticas se desenvolvem mais que outras, apesar de terem condições naturais e de infraestrutura semelhantes. O nível de coopetição do destino representa um recurso, uma fonte de vantagens competitivas (coopetitivas), assim como representa o nível de maturidade da rede interorganizacional. De esta forma, os estudos por vezes consideram coopetição como uma variável explicativa (independente) e outras vezes como uma variável explicada (dependente) e a relacionam com diversos outros construtos que atuam sobre a competitividade do destino (ver Figura 1).

Pelos resultados desta análise se pode concluir que a coopetição poderá ser uma perspectiva complementar às teorias de competitividade de destinos, assim como complementar à teoria baseada em recursos e em capacidades (Della Corte $\&$ Sciarelli, 2012), pois para ambas a coopetição representa mais uma dimensão que deve ser considerada com especial atenção, para determinar o peso que exerce sobre o resultado final de competitividade, atratividade e desempenho do destino (co-produção).

No turismo poucos autores desenvolveram modelos para medir esta capacidade nos destinos turísticos, mas passo a passo estão delineando as variáveis de contexto, portanto a tendência futura é que os estudos evoluam para apresentar sistemas complexos e multidimensionais que possibilitem medir a capacidade de coopetição dos destinos turísticos. Apesar de a linha futura de investigação deste construto ser muito ampla devido ao baixo número de estudos publicados, recomenda-se uma atenção especial ao desenvolvimento 
de modelos explicativos deste construto considerado o destino como um sistema de coopetição. Estas propostas contribuíram para testes empíricos e consequente aprimoramento e adaptação deste construto ao turismo.

\section{REFERÊNCIAS}

Aldamiz-Echevarría, C.; Aguirre, M. S. \& Aparicio, M. G. (2014). Orígenes, elementos determinantes y resultados de un exitoso proceso de colaboración entre competidores y otros agentes: el cluster de la Alta Cocina Vasca/Origins, determinant factors and outcomes of a successful collaborative process among competitors and other actors: the cluster of Basque Haute Cuisine. Cuadernos de Gestión, 4 (2), 51.

Barney, J. (1991). Firm resources and sustained competitive advantage. Journal of management, 17 (1), 99-120.

Baruch, Y. \& Lin, C. (2012). All for one, one for all: Coopetition and virtual team performance. Technological Forecasting and Social Change, 79 (6), 1155-1168.

Bengtsson, M. \& Johansson, M. (2014). Managing coopetition to create opportunities for small firms. International Small Business Journal, 32 (4), 401-427.

Bengtsson, M. \& Kock, S. (2000). Coopetition in business Networks-to cooperate and compete simultaneously. Industrial Marketing Management, 29 (5), 411-426.

Bengtsson, M. \& Kock, S. (2014). Coopetition-Quo vadis? past accomplishments and future challenges. Industrial Marketing Management, 43 (2), 180-188.

Botsman, R. \& Rogers, R. (2011). What's mine is yours: The Rise of Collaborative Consumption. New York, NY: Collins.

Bouncken, R. B. \& Kraus, S. (2013). Innovation in knowledge-intensive industries: The doubleedged sword of coopetition. Journal of Business Research, 66 (10), 2060-2070.

Brandenburger, A. M. \& Nalebuff, B. J. (1996). Co-opetition: A revolutionary mindset that combines competition and cooperation in the marketplace. Harvard Business School Press, Boston.

Camarinha-Matos, L. M. \& Afsarmanesh, H. (2006). Collaborative networks: Value creation in a knowledge society. Knowledge Enterprise, IFIP, 207, 26-40.

Cherington, P. T. (1913). Advertising as a business force Doubleday, Page for the Associated advertising clubs of America.

Chim-Miki, A.F.; Batista-Canino, R.M. \& Gândara, J.M. (2015). Analizando el factor Coopetición en los Monitores de competitividad: Una comparación entre Brasil, España y TTCI. En: XII 
ISSN: 1983-7151

Seminário da Associação Nacional de Pesquisa e Pós-Graduação em Turismo (ANPTUR), Natal/RN, Brasil.

Chin, K., Chan, B. L. \& Lam, P. (2008). Identifying and prioritizing critical success factors for coopetition strategy. Industrial Management \& Data Systems, 108 (4), 437-454.

Contractor, F. J. \& Lorange, P. (1988). Why should firms cooperate? the strategy and economics basis for cooperative ventures. Cooperative Strategies in International Business, 1, 3-30.

Crowley, L. G. \& Karim, M. A. (1995).Conceptual model of partnering. Journal of Management in Engineering, 11 (5), 33-39.

Dagnino, G. \& Padula, G. (2002). Coopetition strategic: Towards a new kind of interfirm dynamics. Paper presented at the The European Academy of Management. Stockholm: Second Annual Conference-Innovative Research in Management.

Dagnino, G. B. (2012). Handbook of research on competitive strategy. Edward Elgar Publishing.

Deguzman, G. V. \& Tang, A.I. (2011). Working in the "UnOffice": A Guide to Coworking for Indie Workers, Small Businesses, and Nonprofits. San Francisco: Night Owls Press.

Della Corte, V. \& Aria, M. (2016). Coopetition and sustainable competitive advantage. The case of tourist destinations. Tourism Management, 54 (1), 524-540.

Della Corte, V. \& Sciarelli, M. (2012). Can coopetition be source of competitive advantage for strategic networks? Corporate Ownership \& Control, 10 (1), 363-379.

Edgell, D. L. \& Haenisch, T. R. (1995). Coopetition: Global tourism beyond the millennium. Charting the course for education, government, and commerce International Policy Publishing.

Ellison, S. D. \& Miller, D. W. (1995). Beyond ADR: Working toward synergistic strategic partnership. J. Mgmt. in Engrg., ASCE, 11 (6), 44-54.

Eriksson, P. E. (2008). Procurement effects on coopetition in client-contractor relationships. Journal of Construction Engineering and Management, 134 (2), 103-111.

Fernandez, A. S., Le Roy, F. \& Gnyawali, D. R. (2014). Sources and management of tension in co-opetition case evidence from telecommunications satellites manufacturing in Europe. Industrial Marketing Management, 43 (2), 222-235.

Fyall, A., Garrod, B. \& Wang, Y. (2012). Destination collaboration: A critical review of theoretical approaches to a multi-dimensional phenomenon. Journal of Destination Marketing \& Management, 1 (1), 10-26.

Ghobadi, S. \& D'ambra, J. (2012). Knowledge sharing in cross-functional teams: a coopetitive model. Journal of Knowledge Management, 16 (2), 285-301. 
Gnyawali, D. R. \& Park, B. R. (2009). Co-opetition and technological innovation in small and medium-sized enterprises: A multilevel conceptual model. Journal of Small Business Management, 47 (3), 308-330.

Guo, X., Zheng, X., Ling, L. \& Yang, C. (2014). Online coopetition between hotels and online travel agencies: From the perspective of cash back after stay. Tourism Management Perspectives, 12, 104-112.

Huang, H. C. \& Chu, W. (2015). Antecedents and consequences of co-opetition strategies in small and medium-sized accounting agencies. Journal of Management \& Organization, 21 (6), 812-834.

Hermes, R. R., Resende, L. M. \& Júnior, P. P. A. (2013). Análise coopetitiva-um modelo para redes horizontais de empresas. Revista Brasileira de Gestão e Desenvolvimento Regional, 9 (2).

Hung, S. W. \& Chang, C. C. (2012). A co-opetition perspective of technology alliance governance modes. Technology Analysis \& Strategic Management, 24 (7), 679-696.

Kim, S., Kim, N., Pae, J. H. \& Yip, L. (2013). Cooperate "and" compete: Coopetition strategy in retailer-supplier relationships. Journal of Business \& Industrial Marketing, 28 (4),263-275.

Kylanen, M. \& Mariani, M. M. (2012). Unpacking the temporal dimension of coopetition in tourism destinations: Evidence from finnish and italian theme parks. Anatolia, 23 (1), 61-74.

Kylänen, M. \& Rusko, R. (2011). Unintentional coopetition in the service industries: The case of pyhä-luosto tourism destination in the finnish lapland. European Management Journal, 29 (3), 193-205.

Krippaehne, R. C., Mccullouch, B. G. \& Vanegas, J. A. (1992). Vertical business integration strategies for construction. Journal of Management in Engineering, 8 (2), 153-166.

Lacoste, S. (2011). "Vertical coopetition": The key account perspective. Industrial Marketing Management, 41 (4), 649-658.

Lin, C., Wang, Y., Tsai, Y. \& Hsu, Y. (2010). Perceived job effectiveness in coopetition: A survey of virtual teams within business organizations. Computers in Human Behavior, 26 (6), 1598-1606.

Limoubpratum, C., Shee, H. \& Ahsan, K. (2015). Sustainable distribution through coopetition strategy. International Journal of Logistics Research and Applications, 18 (5), 424-441.

Liu, M. L., Liu, N. T., Ding, C. G. \& Lin, C. P. (2015). Exploring team performance in high-tech industries: Future trends of building up teamwork. Technological Forecasting and Social Change, 91, 295-310.

Lorgnier, N.; Su, C. (2014). Considering coopetition strategies in sport tourism networks: A look at the nonprofit nautical sports clubs on the northern coast of France. European Sport Management Quarterly, 14 (1), 87-109. 
Luo, Y. A. (2004). Coopetition perspective of MNC-host government relations. Journal of International Management, 10 (4), 431-451.

Luo, Y. (2005). Toward coopetition within a multinational enterprise: A perspective from foreign subsidiaries. Journal of World Business: JWB, 40 (1), 71-90.

Luo, Y. (2007). A coopetition perspective of global competition. Journal of World Business: $J W B, 42(2), 129-144$.

Luo, X., Slotegraaf, R. J. \& Pan, X. (2006). Cross-functional "coopetition": The simultaneous role of cooperation and competition within firms. Journal of Marketing, 70 (2), 67-80.

Meho, L. I. \& Yang, K. (2007). Impact of data sources on citation counts and rankings of LIS faculty: Web of science versus scopus and google scholar. Journal of the American Society for Information Science and Technology, 58 (13), 2105-2125.

Mohr, J. \& Spekman, R. (1994). Characteristics of partnership success: Partnership attributes, communication behavior, and conflict resolution techniques. Strategic Management Journal, 15 (2), 135-152.

Norman, P. M. (2002). Protecting knowledge in strategic alliances: Resource and relational characteristics. The Journal of High Technology Management Research, 13 (2), 177-202.

Padula, G. \& Dagnino, G. B. (2007). Untangling the rise of coopetition: The intrusion of competition in a cooperative game structure. International Studies of Management \& Organization, 37 (2), 32-52.

Park, B., Srivastava, M. K. \& Gnyawali, D. R. (2014). Impact of coopetition in the alliance portfolio and coopetition experience on firm innovation. Technology Analysis and Strategic Management, 26 (8), 893-907.

Pesämaa, O., Pieper, T., Da Silva, R. V., Black, W. C. \& Hair, J. F. (2013). Trust and reciprocity in building inter-personal and inter-organizational commitment in small business cooperatives. Journal of Co-operative Organization and Management, 1 (2), 81-92.

Raza-Ullah, T., Bengtsson, M. \& Kock, S. (2014). The coopetition paradox and tension in coopetition at multiple levels. Industrial Marketing Management, 43 (2), 189-198.

Ring, P. S. \& Van De Ven, A. H. (1994). Developmental processes of cooperative interorganizational relationships. Academy of Management Review, 19 (1), 90-118.

Ritchie, J. B., \& Crouch, G. I. (2003). The competitive destination: A sustainable tourism perspective. Cabi. 
Ritala, P. \& Hurmelinna-Laukkanen, P. (2009). What's in it for me? creating and appropriating value in innovation-related coopetition. Technovation, 29 (12), 819-828.

Ritala, P. \& Hurmelinna-Laukkanen, P. (2013). Incremental and radical innovation in coopetition - The role of absorptive capacity and appropriability. Journal of Product Innovation Management, 30 (1), 154-169.

Rusko, R. (2011). Exploring the concept of coopetition: A typology for the strategic moves of the finnish forest industry. Industrial Marketing Management, 40 (2), 311-320.

Taylor, P., Mcrae-Williams, P. \& Lowe, J. (2007). The determinants of cluster activities in the Australian wine and tourism industries. Tourism Economics, 13 (4), 639-656.

Timón, D. A. B. (2004). El concepto de destino turístico: una aproximación geográficoterritorial. Estudios Turísticos, 160, 45-68.

Tinoco, J. K. \& Sherman, B. W. (2014). Something old is new again: airline-airport consortia and key stakeholder benefits. World Review of Intermodal Transportation Research, 54 (1), 1-17.

Tsai, W. (2002). Social structure of "Coopetition" within a multiunit organization: Coordination, competition, and intraorganizational knowledge sharing. Organization Science (Providence, R.I.), 13 (2), 179-190.

Tuohino, A. \& Konu, H. (2014). Local stakeholders' views about destination management: who are leading tourism development? Tourism Review, 69 (3), 202-215.

Van Der Zee, E. \& Vanneste, D. (2015). Tourism networks unravelled; a review of the literature on networks in tourism management studies. Tourism Management Perspectives, 15, 46-56.

Vanti, N. (2002). Da bibliometria à webometria: uma exploração conceitual dos mecanismos utilizados pra medir o registro da informação e a difusão do conhecimento. Ciência da Informação, 31 (2), 152-162.

Von Friedrichs Grängsjö, Y. (2003). Destination networking: Co-opetition in peripheral surroundings. International Journal of Physical Distribution \& Logistics Management, 33 (5), 427-448.

Von Neumann, J. \& Morgenstern, O. (2007). Theory of games and economic behavior. Princeton university press.

Wang, Y. \& Krakover, S. (2008). Destination marketing: Competition, cooperation or coopetition? International Journal of Contemporary Hospitality Management, 20 (2), 126-141.

Werner, K., Dickson, G. \& Hyde, K. F. (2015). Learning and knowledge transfer processes in a megaevents context: The case of the 2011 Rugby World Cup. Tourism management, 48, 174-187. 
Wilhelm, M. M. \& Kohlbacher.F. (2011). Co-opetition and knowledge co-creation in Japanese supplier-networks: The case of Toyota. Asian Business \& Management, 10 (1), 66-86.

Yilmaz Borekci, D., Rofcanin, Y. \& Gürbüz, H. (2015). Organisational resilience and relational dynamics in triadic networks: a multiple case analysis. International Journal of Production Research, 53 (22), 6839-6867. 